\title{
Análise da Estrutura, Conduta e Desempenho da Indústria Processadora de Soja no Brasil no Período de 2003 a 2010
}

\author{
Aline Fumie Sediyama ${ }^{1}$, Luiz Gonzaga de Castro Júnior², \\ Cristina Lelis Leal Calegario ${ }^{3}$ e Paulo Henrique de Lima Siqueira ${ }^{4}$
}

Resumo: Baseando-se no arcabouço teórico da Economia Industrial, o presente estudo teve como objetivo analisar a estrutura da indústria processadora de soja, bem como a conduta das empresas e o desempenho do setor no Brasil. Considerando-se o mercado relevante da indústria processadora de soja, foram analisados os índices de concentração das processadoras de acordo com o valor em vendas e as estratégias determinantes da localização das unidades processadoras de soja das principais empresas (Bunge, Cargill, ADM e Louis Dreyfus), verificando as transformações que ocorreram de 1990 a 2010. Para analisar o desempenho do setor no País, foram realizadas análises estatísticas, como matriz de correlação e o método da regressão múltipla por Mínimos Quadrados Ponderados. De maneira geral, no Brasil, ainda há uma tendência de aumento na quantidade de unidades processadoras de soja. Porém, em 2010, o número de unidades paradas foi maior, indicando que não são todas as processadoras que estão utilizando plenamente os recursos. Verificou-se que a concentração das processadoras de soja, de certa forma, não tem limitado o desempenho do setor, mas os custos não estão sendo plenamente repassados pelos produtores de soja aos preços.

Palavras-chaves: estrutura, conduta, desempenho, processadoras de soja.

Abstract: Based on the Industrial Economics theory, this study aimed to analyze the soybean processing industry structure, corporate conduct and performance in Brazil. Considering the relevant market of soybean processing industry, it was analyzed the concentration index of soybean processors with sales and strategies determinants of the plants location of major companies that process soybean (Bunge, Cargill, ADM and Louis

1 Mestranda em administração pela Universidade Federal de Lavras (Ufla). E-mail: alinesediyama@yahoo.com.br

2 Professor de comercialização, derivativos agropecuários, economia da Universidade Federal de Lavras (Ufla). E-mail: gonzaga.ufla@gmail.com

3 Professora de Economia Industrial da Universidade Federal de Lavras (Ufla). E-mail: ccalegario@dae.ufla.br

4 Professor de micro, macro e economia brasileira da Universidade Federal de Lavras (Ufla). E-mail: p33108@hotmail.com 
Dreyfus), analyzing changes from 1990 to 2010. To analyze the sector performance in Brazil, matrix correlation and multiple regression method of weighted least squares statistical analyses were used. Overall, in Brazil, there is still an increase trend in the number of soybeans processing plants. However, in 2010, the number of non-operating plants was higher, showing that not all processors are fully using resources. It was found that the concentration of soybean processors is not limiting the performance of the sector, but the costs have not been fully transferred by soybean producers to prices.

Key-words: structure, conduct, performance, soybean processors.

Classificação JEL: L10.

\section{Introdução}

A soja em grãos representa grande parcela da exportação de commodities do Brasil. De acordo com dados do IBGE (Instituto Brasileiro de Geografia e Estatística), de 1990 até 2011, a quantidade produzida de soja em grão apresentou Taxa Geométrica de Crescimento (TGC) ${ }^{5}$ de $7,2 \%$, provocada tanto pela expansão da área colhida (TGC de 4,9\%) quanto pelo crescimento da produtividade (TGC de 2,20\%).

Apesar de o Brasil produzir várias oleaginosas, como amendoim, caroço de algodão, mamona, oiticica, babaçu, girassol e granola, a soja em grão e seus derivados representam importante parcela do mercado brasileiro de oleaginosas em produção, uso e comércio.

Dentre os grandes produtores mundiais de soja (Estados Unidos, Brasil e Argentina), o Brasil é o que tem o maior potencial de expansão da área cultivada, podendo, dependendo das necessidades de consumo do mercado de farelo e de óleo, mais do que duplicar sua atual produção e, em curto prazo, constituir-se no maior produtor e exportador mundial de soja e seus derivados (DALL'AGNOL et al., 2004).

Os segmentos do sistema agroindustrial da soja são submetidos a um novo ambiente competitivo e ainda passam por importantes mudanças, ao mesmo tempo em que tentam readequar suas estratégias, visando obter

5 Calculada pelo antilog do parâmetro $\beta_{1}$ da regressão $\ln \left(Y_{1}\right)=\beta 0+\beta_{1} T+$ ui, em que $Y_{i}$ é o valor da quantidade produzida de soja em grãos, ou a área ou a produtividade e $\mathrm{T}$, a variável tendência, calculado pelo autor. ganhos de competitividade. Algumas principais mudanças que estão impactando a cadeia da soja são: o deslocamento da produção agrícola rumo aos cerrados (especialmente o Centro-Oeste brasileiro), o desenvolvimento de novos corredores de exportação, as ineficiências estruturais da indústria processadora, consequência do processo de concentração (fusão e aquisições) e a adoção de novas tecnologias.

Mas um dos aspectos mais aparentes no sistema agroindustrial da soja é a formação de grupos empresariais distintos na organização e conduta da indústria de esmagamento, refino e derivados. Em função de níveis diferenciados de integração vertical dentro da cadeia e diversificação para outros negócios além da soja, Buainaim et al. ([200-]) argumentam que, no esmagamento, o foco estratégico predominante é liderança em custos (baseada fortemente em economias de escala, busca de redução da capacidade ociosa, logística eficiente, inovação em processos), ao passo que no estágio de derivados predomina a diferenciação de produtos (com forte orientação para segmentação de mercados, promoção/marca e inovação de produtos).

A maioria das empresas esmagadoras de soja que atuam no Brasil tem forte orientação para liderança em custos, ou seja, visam estratégias que diminuem os custos por unidades de produção, uma vez que buscam explorar o sistema logístico para obterem maior eficiência produtiva.

Há alguns fatores que são decisivos para que a indústria processadora de soja alcance a liderança em custo, tais como: aumentar a escala de produção, proporcionando custos médios 
de produção menores por unidade produzida; diminuir a capacidade ociosa que proporcione redução dos custos médios; aumentar a eficiência na logística, fundamental para adquirir matéria-prima e para a distribuição do produto; e melhorar a gestão financeira, reduzindo riscos frente à volatilidade dos preços, lidando adequadamente com os recursos, os juros e os créditos.

Com isso, o processo de concentração da indústria esmagadora de soja, identificado em outros estudos referentes à década de 90, acentuou-se no início da década de 2000 (CARVALHO e AGUIAR, 2005). Além desse movimento de concentração nas atividades de processamento e comercialização de grãos, Souza (2007) verificou que grupos multinacionais da agroindústria, como a Bunge e a Cargill, realizaram intensos movimentos de aquisições no Brasil no final da década de 90, criando subsidiárias na industrialização de fertilizantes. $\mathrm{O}$ agricultor, além de ser fornecedor de insumos, agora é também cliente diante da indústria de fertilizantes pertencente ao mesmo grupo empresarial.

A partir de 2000, alguns estudos mostraram queopodermonopsônicose manifestaria por meio do pagamento de preços menores aos produtores de soja, nos mercados em que a concentração fosse maior. Os resultados sugeriram que era viável para as empresas processadoras o exercício de poder de mercado em relação aos produtores de soja e que o exercício de poder se daria de maneira mais intensa onde os processadores tivessem maior poder de barganha em relação aos produtores de soja, como em regiões mais afastadas dos portos de embarque (CARVALHO, 2004; CARVALHO e AGUIAR, 2005).

Apesar de o Brasil ter grande potencial para a produção de soja e de aumento de capacidade de processamento, muitas mudanças ocorreram na economia e especificamente no mercado agrícola brasileiro e mundial nos últimos dez anos, como o incentivo à produção de biocombustível, o maior protecionismo das áreas nativas e a crise de crédito financeiro de 2008. Dessa forma, torna- -se importante analisar as mudanças estruturais na indústria processadora de soja e os impactos dessas na conduta e desempenho do setor durante os últimos anos.

Para tanto, o presente estudo tem como objetivo analisar a estrutura da indústria por meio da mensuração da concentração de mercado das indústrias processadoras de soja; a conduta das empresas pela identificação das estratégias determinantes da localização das principais empresas processadoras de soja do Brasil nos últimos anos; e o desempenho do setor no Brasil através dos determinantes dos preços recebidos pelos produtores de soja, das unidades processadoras ativas e do nível de exportação.

Além dessa introdução, o presente estudo foi dividido em cinco seções. Na próxima, estão delineadas as mudanças ocorridas no ambiente competitivo das indústrias processadoras de soja. A seção seguinte se refere aos conceitos teóricos. Depois, são mencionados material e métodos utilizados para a realização deste trabalho. $\mathrm{Na}$ seção seguinte são analisados e discutidos os resultados obtidos. Por último, estão as considerações finais.

\section{Caracterização da indústria de soja no Brasil}

A indústria de esmagamento da soja extrai, refina e processa derivados do óleo e seus principais produtos são o óleo bruto, o óleo refinado e o farelo de soja, além de outros em produção ou potencialmente passíveis de produção. Este segmento proporciona as maiores potencialidades de competitividade da cadeia produtiva, pelas possibilidades de diferenciação e da consequente agregação de valor (BUAINAIM et al., [200-]).

A evolução da capacidade instalada de processamento de soja e a sua localização têm dependido, basicamente, do crescimento da produção agrícola da soja e de seu deslocamento espacial, influenciando na formação dos custos dos setores industriais da cadeia (MAGALHÃES, 1998). 
Os estados do Sul do Brasil e São Paulo foram os pioneiros na produção da soja, devido às condições edafoclimáticas ${ }^{6}$ favoráveis e à proximidade dos portos de embarques.

Segundo Warnken (1999), antes de 1970, a indústria de processamento de soja consistia em grupodepequenasfábricas,localizadas, sobretudo, em São Paulo e no Rio Grande do Sul. Mas, com o aumento da produção dessa commodity no Brasil, houve um acompanhamento por parte das indústrias processadoras, apresentando mudança estrutural em termos de processamento de soja. Houve implantação de unidades modernas, com expansão da capacidade de processamento.

Com o esgotamento dessas áreas de expansão nos estados da região Sul do Brasil, em virtude da diminuição da produtividade decorrente das restrições de crédito oficial e da maior diversificação das lavouras para a redução de riscos, com a produção de milho, algodão e pastagens cultivadas, observou-se menor crescimento em área na cultura da soja, a partir de 1980. Entretanto, em Mato Grosso, Mato Grosso do Sul, Goiás, Maranhão, Minas Gerais e Bahia, a expansão da fronteira agrícola foi responsável pelo incremento do cultivo da soja nestes estados (IGREJA et al., 1988).

Com isso, a capacidade de produção, que era de cerca de 40 mil toneladas/dia em 1977, mais que dobrou em 1982, quando foi para o patamar de 90 mil toneladas/dia. Após um crescimento da capacidade mais suave durante a década de 80 e a primeira metade da década de 90, em 1995 a capacidade instalada havia passado para 116 mil toneladas/dia, e a maior parcela estava concentrada em plantas de mais de 1.499 toneladas/dia (MAGALHÃES, 1998).

O novo parque industrial enfrentou problemas de capacidade ociosa com a produção da soja permanecendo estagnada. Dois fatores contribuíram para esse fato: a degradação da rentabilidade das lavouras e o aumento do preço dos insumos agrícolas.

6 Condições de clima e solo que podem ser ou não propícias para a produção de determinadas culturas agrícolas.
Segundo Williams e Thompson (1988), o aumento da capacidade de esmagamento em comparação à produção agrícola de soja não pode ser explicado simplesmente pela criação de capacidade ociosa planejada, a existência de indivisibilidades, ou a constituição de barreiras à entrada de novos concorrentes. O governo federal deu incentivos ao setor, dando vantagens tributárias, como redução dos impostos e isenções para produtos processados, e ajudou com linhas de crédito que beneficiavam as exportações de produtos originados da soja em grão.

As indústrias processadoras de soja precisaram reduzir os custos fixos decorrentes da capacidade ociosa. Uma das maneiras encontrada foi a importação da soja pelo regime de drawback. Conforme Williams e Thompson (1988), as esmagadoras brasileiras poderiam importar soja em grão, processá-la e exportar os subprodutos com isenção de direitos alfandegários, impostos e cotas. Além da isenção de tributos, o governo financiaria essas importações de soja em grão a uma taxa de juros de 4,5\% ao mês, bem inferior à taxa de mercado vigente em meados de 1982, de $7 \%$ a $8 \%$ ao mês. Embora os subprodutos tivessem o prazo de um ano para serem exportados, o prazo máximo do financiamento era de 180 dias.

A tendência de as novas regiões produtoras expandirem sua participação na capacidade de esmagamento nacional reflete o potencial de aumento da oferta com maior produtividade da soja nessas regiões. Se isso é um fator positivo da competitividade dos setores industriais da cadeia de soja, há os aspectos negativos do deslocamento espacial da capacidade de esmagamento, como: a precariedade da infraestrutura básica dessas regiões, principalmente a de transportes, e a distância em relação aos tradicionais portos de exportação dos produtos agroindustriais da soja (MAGALHÃES, 1998).

As dificuldades no transporte terrestre de farelo e de grãos de soja em certas áreas geográficas que comprometem a competitividade do setor poderiam ser superadas utilizando-se o transporte fluvial em uma das maiores malhas fluviais do planeta, com calhas navegáveis todo 
o ano por navios de grande porte, atingindo os mercados externos por via fluvial/ marítima (BUAINAIM et al., [200-]).

A partir da década de 80, uma das estratégias adotadas pelas grandes firmas multinacionais foi o processo de aquisição de empresas nacionais que buscaram consolidar sua atuação no mercado nacional, principalmente na região de expansão (Centro-Oeste), onde o número de empresas existentes no setor era inferior em relação à região tradicional (MEDEIROS e FRAGA, 2002).

Além disso, para diminuir o risco de negociação da soja, as esmagadoras que se deslocavam para a região Centro-Oeste buscavam estabelecer contratos. De acordo com Paes Lemes (2994) 31,5\% dos 200 sojicultores de Goiás e Mato Grosso adotavam formas contratuais híbridas ${ }^{8}$, envolvendo a venda antecipada a processadoras, indústrias de insumo e produtores de soja.

Há duas regiões produtoras e com firmas processadoras no Brasil com características próprias: a região tradicional (Sul) e a região dos cerrados. A primeira tem unidades de produção agrícola de menor escala, com forte presença de cooperativas e maior número de plantas processadoras de soja. Já a segunda apresenta desenvolvimento mais recente, com unidades agrícolas de maior escala e menor número de processadoras.

As empresas líderes buscam aumentar a competitividade logística, procurando estabelecer suas unidades em diferentes regiões do País. Porém, elas encontram uma barreira em relação à exportação de farelo e óleo de soja. A Lei Kandir que, de acordo com a Lei Complementar n. 87 de 1996 no Artigo 3oㅡㄹ isenta de ICMS (Imposto sobre Circulação de Mercadorias e Serviços) operações e prestações que destinem ao exterior mercadorias, inclusive produtos primários e

7 apud Zylbersztajn (2005).

8 De acordo com Zylbersztajn (1995); Casorotto Filho (1998), contratos híbridos são complexos e envolvem relações de longo prazo, arranjos de propriedade parcial de ativos, coprodução, comércio recíproco, contratos de distribuição, alianças estratégicas, joint-ventures, franquias, licenciamentos, contratos de compra e venda a longo prazo, redes de empresas, consórcios e produção compartilhada. produtos industrializados semielaborados, ou serviços, prejudica a venda externa dos produtos derivados de soja, aumentando seus impostos, enquanto beneficia a soja em grão.

Como a soja em grão é o fator de principal custo da produção industrial, as empresas esmagadoras buscam ganhos de escala, aumentando o tamanho da planta industrial para reduzir os custos médios de esmagamento. Dessa forma, se as indústrias esmagadoras conseguem quantidades desejáveis de soja a preços menores, elas conseguem explorar a economia de escala, ganhando, consequentemente, na margem de lucro.

Segundo Magalhães (1998), um aspecto peculiar da competitividade da cadeia é que as novas plantas de esmagamento e refino de óleo de soja na região central do Brasil apresentam capacidade média de processamento maior em relação às plantas da região Sul, podendo apresentarcustos de produção menores em relação às do Sul se conseguirem explorar as economias de escala. E alguns fatores têm possibilitado as empresas explorarem as economias de escala, como o acesso privilegiado à commodity, plantas de grande porte e os investimentos em logística, mantendo uma posição sólida nos mercados internacionais de farelo e óleo de soja.

Entretanto, na década de 90, a capacidade ociosa foi uma das principais fontes de ineficiência da maioria das esmagadoras de soja no Brasil, afetando negativamente sua rentabilidade e, consequentemente, a geração de fundos próprios para investimento (MAGALHÃES, 1998). Carvalho e Aguiar (2005) verificaram, em seu estudo, que a maior capacidade ociosa por parte das firmas processadoras aumenta a concorrência pela compra de soja em grão, refletindo em preços maiores pagos aos produtores, e essa característica é mais significativa nas regiões mais próximas aos portos de embarque, ou seja, menor distância e maior capacidade ociosa tendem a implicar preços maiores pagos aos produtores.

As condições de entrada no mercado se traduzem na barreira de entrada, que é uma vantagem que os vendedores estabelecidos 
em uma indústria têm sobre os vendedores entrantes potenciais, que reflete na capacidade que os primeiros têm de persistentemente poder aumentar seus preços acima do nível competitivo, sem atrair novas firmas para entrar na indústria (BAIN, 1956).

Segundo Farina (2000), as barreiras à entrada podem ter natureza tecnológica (economias de escala ou de escopo em relação ao tamanho do mercado), ou de diferenciação (reputação das empresas já estabelecidas e marcas comerciais).

Dessa forma, as economias de escala que as empresas esmagadoras buscam são caracterizadas como barreiras à entrada, uma vez que as entrantes precisam também apresentar plantas industriais com alta capacidade de produção para concorrer no mercado.

Porém, a tecnologia das indústrias de esmagamento não é caracterizada como barreira à entrada, pois tem tecnologia de fácil acesso a todas as empresas do setor, não apresentando exclusividade de patentes (MAGALHÃES, 1998).

Em 2009, a exportação da soja em grão e os seus derivados apresentou aumento e grande participação nas exportações do País. De acordo com dados da Conab (2010), em 2009, o faturamento da exportação da soja representou $27 \%$ do total das exportações do agronegócio, enquanto participou com $11 \%$ no total dos embarques brasileiros. Os principais destinos da commodity são a União Europeia (Holanda, Alemanha e Espanha), a China e o Japão. Mas um dos problemas enfrentados pelos exportadores brasileiros são as barreiras tarifárias e não tarifárias que os importadores estabelecem.

A soja in natura é mais exportada em comparação aos seus derivados, sendo que um dos fatores que impulsiona essa situação é a Lei Kandir. Mas, segundo Lazzarini e Nunes (2000), a exportação de soja em grão é favorecida também pela ineficiência de muitas processadoras nacionais, onde estão presentes a capacidade ociosa e a logística desfavorável, e o alto custo de carregamento de estoques de soja no País, devido aos juros altos. Para as empresas, não havia necessariamente margens adicionais na agregação de valor ao produto por meio do processamento deste.

O Brasil tem demonstrado pouca ampliação na exportação de óleo de soja, que é a principal fonte de gordura para o mercado interno. A legislação tributária e as características pecuniárias das unidades de processamento são alguns dos fatores para o País apresentar menor grau de competitividade no exterior para esse produto (PINAZZA, 2007).

Para os representantes da indústria de processamento e exportação de soja, é mais vantajoso que a soja seja utilizada dentro do Brasil, em vez de ser exportada, por causa dos tributos altos e do frete que não compensam a grande quantidade de produtos comercializados no exterior.

\section{Modelo Estrutura-Conduta- -Desempenho}

Ao se estudar as empresas agroindustriais, cada vez mais se faz necessário ultrapassar o paradigma da teoria de firma Walrasiana, que desconsidera as relações das firmas com o seu ambiente de mercado. Segundo Zylberztajn (2005), vários estudos já foram realizados no Brasil baseados na teoria da Economia Industrial, focalizando as cadeias produtivas.

As relações entre empresas, mercado e instituições são a essência da teoria da Economia Industrial, que foi reconhecida na literatura na década de 50 como um campo específico da literatura econômica. Para esta teoria, a empresa precisa se adequar às forças ambientais internas e externas para conseguir competir e sobreviver no mercado em que está inserida. E se caracteriza como uma observadora empírica do comportamento das empresas. Dentro desse ramo há duas principais correntes: a abordagem tradicional e a abordagem alternativa (schumpeteriana/institucionalistas).

De acordo com Kupfer e Hasenclever (2002), a primeira corrente estruturou-se progressivamente a partir do trabalho de Joe S. Bain, culminando com a representação teórico-analítica 
proposta por F. M. Scherer, conhecida como modelo Estrutura-Conduta-Desempenho (Modelo ECD). Tem como principal objetivo a análise da alocação dos recursos escassos sob as hipóteses de equilíbrio e maximização dos lucros. Recentemente, alguns desenvolvimentos na matematização dos modelos de empresa e de interação entre essas (teoria dos jogos) levaram os estudiosos a rebatizar esta corrente de Nova Economia Industrial (NEI). Nesse desdobramento há um aumento da importância das condutas empresariais na determinação das estruturas de mercado; a empresa deixa de ser um agente passivo para adotar estratégias arbitrárias. Os principais fundamentos da ação governamental na preservação da concorrência (regulação) e seus efeitos sobre a estrutura da indústria e sobre a estratégia das empresas (defesa da concorrência) são oriundos dessa corrente.

Para Bain, as condutas não importavam a ponto de se considerar que a estrutura - representada por variáveis como grau de concentração ou de barreiras à entrada - determinava direta e inequivocamente o desempenho do mercado. E o desempenho, por sua vez, é avaliado em termos do desvio da taxa de lucro efetiva em relação à taxa ideal em eficiência alocativa - o ótimo de Pareto - o que significa, de fato, o desvio do preço efetivo em relação ao custo marginal de produção (KUPFER e HASENCLEVER, 2002).

O Modelo ECD propõe que as condições básicasdemercado(ofertaedemanda)influenciam a estrutura de mercado. E, por conseguinte, dependendo da estrutura de mercado (número e tamanho relativo dos concorrentes, compradores e vendedores; grau de diferenciação dos produtos; existência de barreira de entrada de novas empresas no mercado, estrutura de custos; integração vertical), a empresa terá uma conduta (política de preços, níveis de cooperação tácita, pesquisa e desenvolvimento, publicidade, investimento, política de fusões e aquisições, decisão de produção) que irá influenciar no desempenho (eficiência produtiva e alocativa; desenvolvimento; pleno emprego; processo técnico; crescimento distributivo).
A relação da estrutura de mercado com o desempenho, passando pela conduta das empresas, resulta nos modelos de concorrência perfeita e monopólio, em que quantidades de empresas menores determinariam os níveis de mercado que estão inseridas. E para o modelo ECD, se uma estrutura de mercado se aproximar do monopólio, seu desempenho será pior.

Mas, segundo Scherer (1970), não existe somente um fluxo direto entre o modelo, mas também os feedbacks; por exemplo, uma conduta de política de preço adotada pelos vendedores pode aumentar ou diminuir as barreiras de entrada, influenciando consequentemente na estrutura do mercado.

Segundo Possas (1990), o modelo ECD também pode ser expresso como a tríade concentração barreiras à entrada - lucratividade. E o elemento estrutural do mercado que habitualmente é associado mais de perto à concentração, bem como as barreiras à entrada, é a presença de economias de escala. Estas podem ser reais ou pecuniárias, distinguindo-se conforme a vantagem nos custos unitários relacionada com o tamanho que proporcione uma economia física de recursos, ou caso contrário, unicamente um poder diferencial de obter preços vantajosos dos próprios produtos ou dos mercados fornecedores de insumos, trabalho e capital.

Sousa (2005) complementa que, devido ao fato de haver pequena, média e grande empresa, já se nota um descompasso na dinâmica de crescimento que estas empresas atravessam. Isso quer demonstrar que existem economias de escala crescente para uns e decrescentes para outros que crescem mais lentamente.

A Escola de Chicago contrapõe-se ao Modelo ECD, afirmando que há livre entrada e saída do mercado e produtos homogêneos. Para os estudiosos dessa corrente, as empresas relativamente maiores seriam capazes de conseguir economia de escala e escopo, pois elas estariam em condições semelhantes para atingir essas vantagens, e os ganhos de eficiência ocorreriam de estruturas mais concentradas.

Enquanto o modelo estrutura-conduta-desempenho acredita numa visão de concorrência 
imperfeita para analisar o comportamento industrial, a Escola de Chicago acredita no modelo de concorrência perfeita (MARTIN, 1993).

\subsection{Estratégia de crescimento}

As empresas buscam formas de crescimento para conseguirem se manter no mercado, que está cada vez mais competitivo. Segundo Azevedo (2000), algumas das estratégias de crescimento são tipicamente ações que visam alterar a estrutura dos mercados e, com isso, permitir uma posição melhor na concorrência junto a rivais - como é o caso de fusões e aquisições, diversificação e integração vertical. Outras constituem ações que buscam uma posição mais favorável das empresas na disputa pelos consumidores, como segmentação de mercado e diferenciação.

Porém, uma das formas de competição que está presente tanto no âmbito nacional e no internacional é a concentração de mercado, que pode ser realizada por meio das fusões e aquisições.

Uma fusão ocorre quando duas ou mais empresas, em geral de porte praticamente igual, combinam-se em uma empresa por uma permuta de ações. As fusões são realizadas para partilhar ou transferir recursos e ganhar em força competitiva. A principal razão para uma fusão é tirar vantagem dos benefícios da sinergia. Quando a combinação de duas empresas resulta em maior eficácia e eficiência do que se conseguia com cada uma delas separadamente, a sinergia foi, então, atingida. Mas se a tendência for de fusões para as empresas tirarem vantagens, é possível que, em períodos de recessão econômica, as empresas tendam a vender sua participação em relação às firmas (WRIGHT et al., 2007; KON, 1999).

Segundo Azevedo (2000), o principal motivo para as firmas realizarem estratégias de crescimento por fusões e aquisições é a presença de economias de escala, em suas diversas formas (reais ou pecuniárias).

Kon (1999) acrescenta que há outros objetivos para a compra de outra empresa: possibilidade de obter ou ampliar as economias de escala quando se encontram em tamanho abaixo do ótimo em relação aos custos; complementaridades que podem ocorrer entre as empresas, como no processo de integração vertical; possibilidade de crescimento com maior velocidade e segurança; possibilidade de dominação do mercado, eliminando rivais e partindo para a monopolização da produção; favorecimento das ações no mercado acionário, caso os fatores financeiros sejam suficientes para unir os capitais em uma empresa.

Fusões e aquisições podem ser de três tipos principais: horizontal, vertical e diversificação. Na horizontal, uma firma se agrega a outra, que desenvolve a mesma atividade; na vertical, ela se une a outra, a montante (fornecedora) ou a jusante (compradora), de sua cadeia de produção e, finalmente, numa diversificação, uma firma se une às outras firmas de diferentes atividades econômicas. A diversificação é concêntrica quando a empresa comprada tem produção, tecnologia, produtos, canais de distribuição e ou mercados similares aos da empresa compradora, $\mathrm{e}$ é diversificação não relacionada ou conglomerada quando a adquirida tem linhas de negócios completamente diferentes (CERTO et al., 2005).

As medidas de concentração pretendem captar de que forma agentes econômicos apresentam um comportamento dominante em determinado mercado e, nesse sentido, os diferentes indicadores consideram as participações no mercado dos agentes segundo diferentes critérios de ponderação (RESENDE e BOFF, 2002).

Resende (1994) define três etapas no desenvolvimento de medidas de estrutura de mercado: a) o grau de concentração nas vendas descrito pelo número e distribuição de tamanho dos vendedores no mercado; b) o grau de concentração nas vendas medidas em termos de participação das maiores firmas no mercado; e c) a intensidade da concentração medida em termos de um índice que considere todas as firmas que atuem em um dado mercado.

As medidas de concentração podem ser classificadas como: parciais ou sumárias, positivas ou normativas. As medidas parciais são aquelas que utilizam apenas uma parte dos dados 
da totalidade das empresas em operação na indústria em consideração, como por exemplo, as razões de concentração. As sumárias requerem dados sobre todas as empresas em operação, como por exemplo, os índices de concentração de Hirschman - Herfindahl e entropia de Theil. As medidas positivas são unicamente função da estrutura aparente do mercado industrial (o nível e a distribuição das parcelas de mercado). $\mathrm{E}$ as medidas normativas consideram a estrutura aparente e os parâmetros comportamentais que estão relacionados com as preferências dos produtores ou consumidores.

\section{Material e métodos}

O mercado relevante sob análise é a indústria processadora de soja onde são oriundos todos os produtos de esmagamento de soja do Brasil. Neste estudo, o modelo conceitual utilizado é apresentado na Figura 1, uma adaptação do modelo de Scherer (1970), abordando a estrutura do mercado, a conduta empresarial e o desempenho do setor.

Na estrutura do mercado, o grau de concentração foi medido por meio dos indicadores: razões de concentração e o índice de $\mathrm{HH}$ de 23

Figura 1. Modelo conceitual do estudo

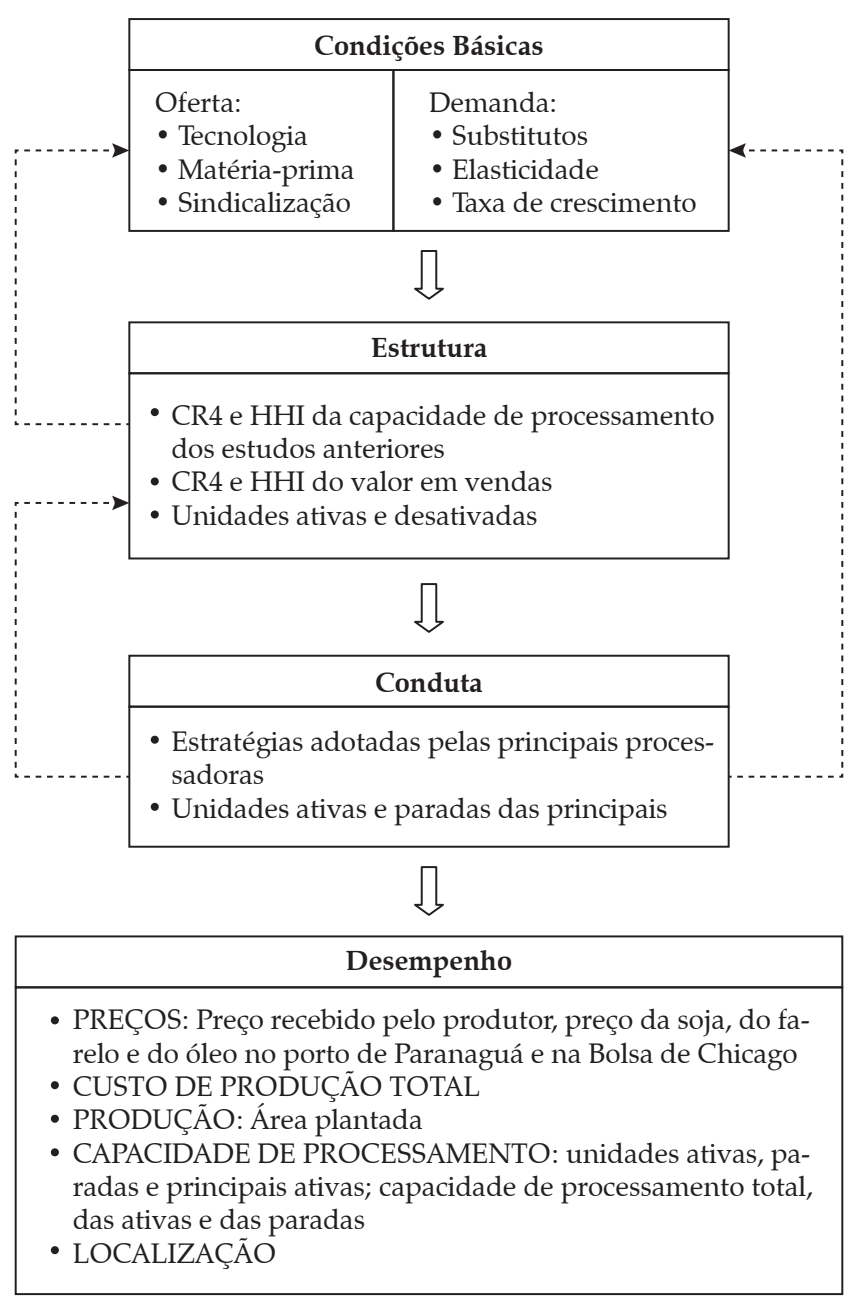

Fonte: Adaptado do modelo de Scherer (1970). 
empresas que possuíam unidades processadoras de soja no País, que foram analisadas de acordo com o valor em vendas (em US\$ milhões) com dados das "Melhores e Maiores" da Revista Exame, do período de 2006 a 2009.

A razão de concentração de ordem $k$ é um índice positivo que fornece a parcela de mercado das $\mathrm{k}$ maiores empresas da indústria $(\mathrm{k}=1,2,3$, ..., n). Assim:

$$
\mathrm{CR}(\mathrm{k})=\sum_{\mathrm{i}=1}^{\mathrm{k}} \mathrm{s}_{\mathrm{i}}
$$

em que:

$\mathrm{CR}_{\mathrm{k}}=$ taxa de concentração das k-ésimas maiores firmas;

$\mathrm{S}_{\mathrm{i}}=$ parcela de mercado da firma i, ou seja, o volume de vendas das empresas;

$\mathrm{k}=$ número de firmas consideradas.

Quanto maior o valor do índice, maior é o poder de mercado exercido pelas $\mathrm{k}$ maiores empresas. Segundo Vasconcelos; Garcia (2005), em termos percentuais, quanto mais próximo de $100 \%$, maior o grau de concentração do setor; quanto mais próximo de $0 \%$, menor o grau de concentração (e, portanto, maior o grau de concorrência) do setor.

Resende; Boff (2002) observam algumas deficiências imediatas dos índices CR: ignorar a presença das $n-k$ empresas menores da indústria; não levar em conta a participação relativa de cada empresa no grupo das $k$ maiores empresas; e não informar sobre a posição das firmas dentro do ranking (turnover); e ignorar o papel das importações. Por isso, é aconselhável a utilização do Índice de Hirschman - Herfindahl $(\mathrm{HH})$ conjuntamente, que se refere à soma dos quadrados das parcelas de mercado de cada empresa, calculado como:

$$
\mathrm{HH}=\sum_{i=1}^{n} S_{i}^{2}
$$

em que:

$\mathrm{Si}=$ parcela decimal de mercado de uma das firmas do mercado analisado;

$\mathrm{N}=$ número total de empresas.
Elevar cada parcela de mercado ao quadrado implica atribuir um peso maior às empresas relativamente maiores. $\mathrm{O}$ índice $\mathrm{HH}$ varia entre 0 e 1 . Dessa forma, quanto maior for o $\mathrm{HH}$, mais elevada será a concentração (menor a concorrência entre os produtores).

Além das 23 empresas cadastradas na revista, também se verificou a concentração das processadoras de soja de acordo com a capacidade de processamento nos estudos realizados por Aguiar (1994), Magalhães (1998); Aguiar e Leismann (2001) ${ }^{9}$; Carvalho (2004) nos anos de 1993, 1995, 1997 e 2003. Devido a dados indisponíveis, não foi possível a continuação da mensuração da concentração em relação à capacidade de processamento nos últimos anos. Com os dados da Abiove, analisou-se a quantidade de unidades ativas e desativadas nos estados brasileiros. Os 13 estados observados foram: Paraná, Mato Grosso, Rio Grande do Sul, Goiás, São Paulo, Mato Grosso, Minas Gerais, Bahia, Santa Catarina, Piauí, Amazonas, Pernambuco e Maranhão, compreendendo o período de 2003 a 2010. O estado de Rondônia não foi incluído, pois apresentou unidade processadora de soja apenas em 2010.

Para analisar a conduta, foram identificadas as estratégias determinantes da localização das unidades processadoras de soja das principais empresas (Bunge, Cargill, ADM e Louis Dreyfus), analisando as transformações que ocorreram nesse período. Diversas informações foram buscadas em periódicos, dissertações e teses, notícias semanais e páginas na internet das grandes esmagadoras de soja, por exemplo.

Para analisar o desempenho do setor no País, foram realizadas análises de regressão múltipla por Mínimos Quadrados Ponderados, para eliminar o problema de heterocedasticidade. O método stepwise foi utilizado para ajudar na seleção das melhores variáveis para o modelo.

As variáveis utilizadas em cada análise estão apresentadas nas Tabelas 1, 2 e 3, bem como os efeitos marginais esperados em cada regressão.

9 apud Carvalho (2004). 
Os três modelos têm como variáveis dependentes o preço recebido pelo produtor em $\mathrm{R} \$ /$ tonelada (Pre), a quantidade de unidades processadoras de soja ativas (Ati) e a quantidade exportada de soja em grão em mil toneladas (QuExp). Os softwares utilizados foram o Gretl (GNU Regression, Econometric and Time-series Library) e o SPSS (Statistical Package for the Social Sciences). Para a tabulação dos dados, as planilhas do Excel foram utilizadas.

Foram utilizados os indicadores de preços, custo de produção total, produção, capacidades de processamento e localização em relação ao porto de Paranaguá. As variáveis preço recebido pelo produtor, custo de produção total e preço FOB da soja, do farelo e do óleo foram deflacionadas segundo IGP-DI (FGV), enquanto os preços da soja, do farelo e do óleo na Bolsa de Chicago foram deflacionados segundo o Índice de Preços no Varejo (CPI-U). O preço FOB da soja, do farelo e do óleo no porto de Paranaguá e o preço da soja, do farelo e do óleo na Bolsa de Chicago foram os mesmos para todos os estados.

Somente os estados do Paraná, Mato Grosso, Rio Grande do Sul, Goiás, São Paulo e Mato Grosso do Sul tinham a variável preço recebido pelo

Tabela 1. Variáveis utilizadas em relação ao preço recebido pelo produtor (Pre) em R\$/toneladas

\begin{tabular}{clc}
\hline Sigla & & Descrição \\
\hline CT & Custo de produção total em R\$/tonelada do produtor & Efeito marginal \\
Prod & Produção em mil toneladas & + \\
Par & Quantidade de unidades processadoras de soja paradas & - \\
CaAti & Capacidade de processamento das unidades ativas em tonelada/dia & + \\
OleFob & Preço FOB do óleo de soja no porto de Paranaguá em R\$/tonelada & + \\
FaChic & Preço do farelo de soja na Bolsa de Chicago em R\$/tonelada & + \\
Loc & Localização dos estados considerando-se 0 para aqueles longe do porto de Paranaguá e 1 para perto & + \\
AR & Área plantada em mil hectares & - \\
\hline
\end{tabular}

Fonte: Elaborado pelos autores.

Tabela 2. Variáveis utilizadas em relação às unidades processadoras ativas (Ati)

\begin{tabular}{|c|c|c|}
\hline Sigla & Descrição & Efeito marginal \\
\hline Prod & Produção em mil toneladas & + \\
\hline Par & Quantidade de unidades processadoras de soja paradas & - \\
\hline CaTo & Capacidade de processamento total em tonelada/dia & + \\
\hline CaPar & Capacidade de processamento das unidades paradas em tonelada/dia & - \\
\hline OleFob & Preço FOB do óleo de soja no porto de Paranaguá em R\$/tonelada & + \\
\hline OleChic & Preço do óleo de soja na Bolsa de Chicago em $\mathrm{R} \$ /$ tonelada & + \\
\hline Loc & Localização dos estados considerando-se 0 para aqueles longe do porto de Paranaguá e 1 para perto & + \\
\hline
\end{tabular}

Fonte: Elaborado pelos autores.

Tabela 3. Variáveis utilizadas em relação à quantidade exportada (QuExp) em mil toneladas

\begin{tabular}{clc}
\hline Sigla & & Descrição \\
\hline Prod & Produção em mil toneladas & Efeito marginal \\
Ati & Quantidade de unidades processadoras de soja ativas & + \\
PriAti & Quantidade de unidades ativas das principais processadoras: ADM, Bunge, Cargill e Louis Dreyfus & - \\
SojFob & Preço FOB da soja no porto de Paranaguá em R\$/tonelada & + \\
SojChic & Preço da soja na Bolsa de Chicago em R\$/tonelada & + \\
Loc & Localização dos estados considerando-se 0 para aqueles longe do porto de Paranaguá e 1 para perto & + \\
FaFob & Preço FOB do farelo de soja no porto de Paranaguá em R\$/tonelada & - \\
\hline
\end{tabular}

Fonte: Elaborado pelos autores. 
produtor (Pre). Desta forma, para que se tivesse um aumento da amostra, foram considerados, para os estados de Minas Gerais e Bahia, o preço recebido pelo produtor do estado de Goiás. No entanto, esses oito estados possuem o próprio custo de produção total. Então, para análise do preço recebido pelo produtor e do custo de produção total, a amostra compreendeu os oito estados, enquanto que, para as outras análises, foram considerados os 11 estados.

Os dados foram obtidos por meio da Associação Brasileira da Indústria de Óleos Vegetais (Abiove), do Anuário da Agricultura Brasileira (Agrianual) de 2004 a 2011, da Associação Nacional dos Exportadores de Cereais (Anec), da Companhia Nacional de Abastecimento (Conab) e do Ministério do Desenvolvimento, Indústria e Comércio Exterior (MDIC).

Para análise do desempenho, Amazonas e Pernambuco foram excluídos da análise por não apresentarem área plantada de soja, produção e quantidade exportada, apesar de terem uma processadora de soja em cada estado, embora a unidade de Pernambuco tenha sido desativada a partir de 2007.

Com isso, os dados utilizados foram observados em forma de painel (11 estados com oito observações cada - 2003 a 2010), totalizando 88 observações, lembrando que as variáveis (Pre) e (CT), foram consideradas em apenas oito estados.

O método dos mínimos quadrados ponderados (MQP) é utilizado para correção de um dos problemas da regressão múltipla, que é a heterocedasticidade (variância não constante).

Segundo Gujarati (2006), os mínimos quadrados ponderados minimiza a soma ponderada dos quadrados dos resíduos:

$$
\sum \mathrm{w}_{\mathrm{i}} \hat{\mathrm{u}}_{\mathrm{i}^{2}}=\sum \mathrm{w}_{\mathrm{i}}\left(\mathrm{Y}_{\mathrm{i}}-\beta_{1}-\beta_{2} \mathrm{X}_{\mathrm{i}}\right)^{2}
$$

Em que $\beta_{1}$ e $\beta_{2}$ são os estimadores de mínimos quadrados ponderados e em que os pesos $\mathrm{w}_{1}$ são inversamente proporcionais à variância de $\mathrm{u}_{\mathrm{i}}$.

\section{Resultados e discussão}

\subsection{Estrutura de mercado}

Com os estudos de Aguiar (1994), Magalhães (1998), Aguiar e Leismann (2001) apud Carvalho (2004), observou-se um aumento nos índices de Herfindahl-Hirschman (HHI) e o CR4 das principais esmagadoras de soja nos estados produtores e no Brasil, quando comparado à capacidade de processamento das indústrias.

Em 1993, as quatro maiores esmagadoras de soja em relação à capacidade de processamento do País, dentre 67 empresas, eram a Ceval $(16,87 \%)$, Cargill $(6,43 \%)$, Sadia $(6,18 \%)$ e Sanbra $(5,90 \%)$. O CR4 e o HHI apresentados, 34,39\% e 0,049 , podem ser considerados de baixa concentração de mercado. Com o HHI e o CR4 dos estados, percebeu-se que, no Distrito Federal e em Pernambuco, havia apenas uma unidade esmagadora de soja, enquanto na Bahia existiam duas unidades. Minas Gerais, Mato Grosso e Santa Catarina apresentam poucas unidades processadoras (AGUIAR, 1994; MAGALHÃES, 1998; AGUIAR e LEISMANN, 2001 apud CARVALHO, 2004).

No outro ano observado, em 1995, houve aumento nos índices HHI e CR4, de 0,075 e 44,6, respectivamente, em relação a 1993, no Brasil. Quando observados os estados, Mato Grosso do Sul, Rio Grande do Sul e São Paulo apresentaram aumento do índice CR4, demonstrando uma pequena elevação na concentração da capacidade de esmagamento das quatro maiores firmas. Os mesmos estados que apresentaram o CR4 100\% em 1993 continuaram apresentando maior concentração, e apareceram Ceará e Piauí como novos estados com unidades processadoras. Nesse período, com os estados apresentando tendência à concentração, pode-se demonstrar que as empresas estão preferindo a instalação de unidades de esmagamento com capacidades maiores e estão buscando a proximidade da 
Tabela 4. CR4, CR6 e Índices de Herfindahl-Hirschman (HHI) de 2006 a 2009 no Brasil

\begin{tabular}{ccccc}
\hline & $\mathbf{2 0 0 6}$ & $\mathbf{2 0 0 7}$ & $\mathbf{2 0 0 8}$ & $\mathbf{2 0 0 9}$ \\
\hline CR4 & $69,56 \%$ & $64,12 \%$ & $61,68 \%$ & $58,64 \%$ \\
CR6 & $79,39 \%$ & $74,21 \%$ & $72,08 \%$ & $70,52 \%$ \\
HHI & 0,1631 & 0,139096 & 0,1408 & 0,1204 \\
\hline
\end{tabular}

Fonte: Elaborado pelos autores com dados das “Melhores e Maiores” da Revista Exame de 2006, 2007, 2008 e 2009.

Figura 2. Estratificação da capacidade instalada por tamanho de planta

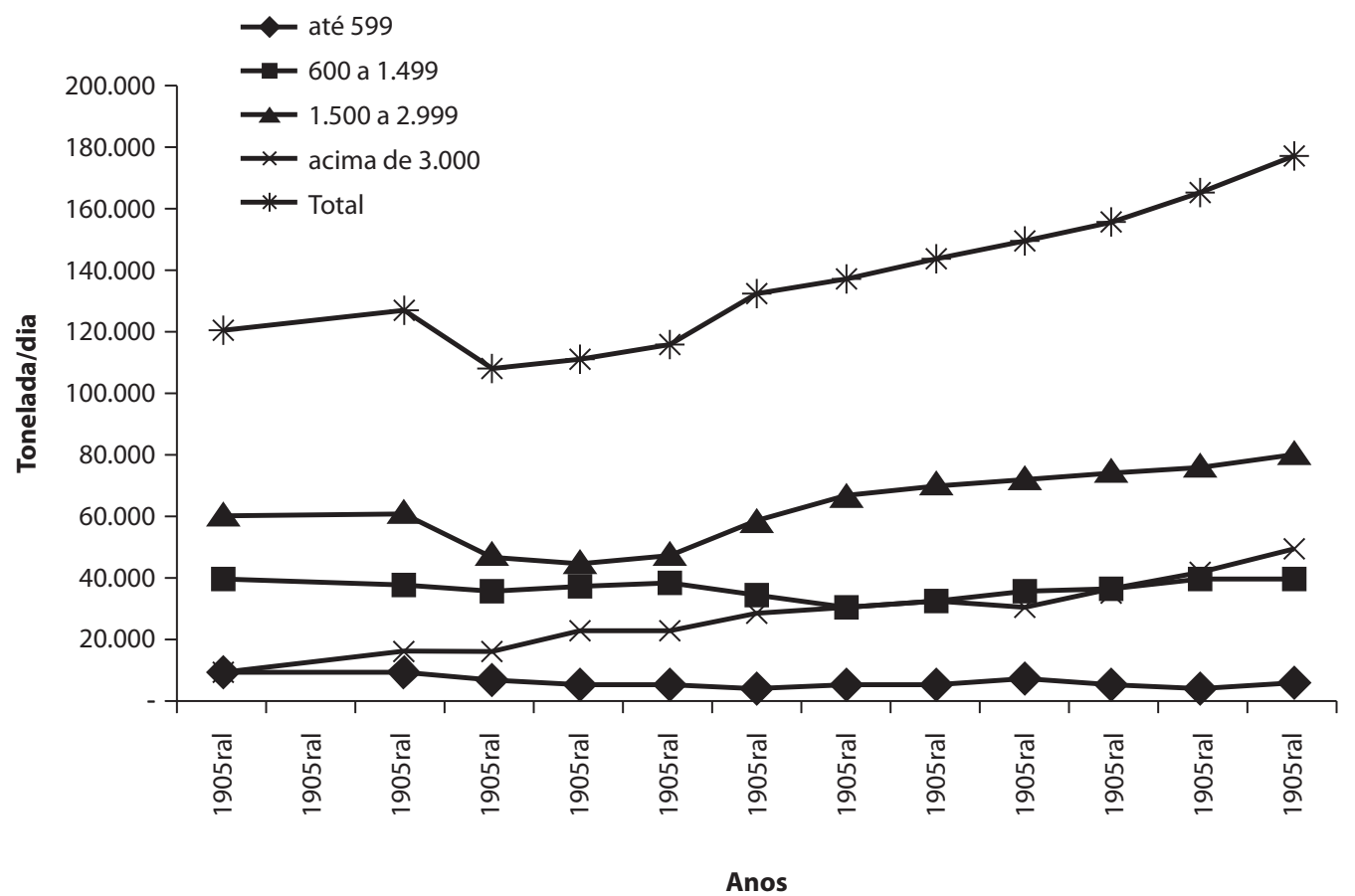

Fonte: Dados da Abiove, 2011.

matéria-prima (AGUIAR, 1994; MAGALHÃES, 1998; AGUIAR e LEISMANN, 200110).

Com o estudo de Carvalho (2004), observa-se que o Brasil apresentou, em 2003, um aumento na concentração da capacidade de esmagamento de soja em relação aos anos anteriores. As quatro maiores empresas nesse ano eram: Bunge Alimentos, com 19,96\% da parcela de mercado, a Cargill, com 9,26\% , a ADM, com 7,96\% e a Coinbra, com $6,65 \%$. Há três estados que apresentaram CR4 igual a 100\% nos períodos analisados, demonstrando a constante concentração das processadoras: Bahia, Minas Gerais e Piauí. E nesse ano, observa-se que Distrito Federal, Ceará

10 apud Carvalho, 2004. e Pernambuco não apresentaram capacidade de esmagamento, enquanto Amazonas iniciou as atividades de processamento.

Com a análise desenvolvida neste estudo, a concentração das processadoras mensuradas, de acordo com os dados do valor em vendas (US\$ milhões), indicou que, nos anos observados, houve redução no $\mathrm{CR} 4, \mathrm{CR} 6$ e no índice Herfindahl-Hirschman (HHI), representando menor concentração das maiores indústrias processadoras de soja (Tabela 4).

Cabe salientar que esses dados têm como base o faturamento das maiores empresas do agronegócio processadoras de soja da Revista Exame, e não da capacidade de esmagamento, conforme realizados nos estudos anteriores. 
Verifica-se, na Figura 2, que houve aumento na capacidade de processamento das unidades industriais, contemplandotantoas unidadesativas quanto as paradas. As unidades com capacidade acima de 3.000 toneladas/dia aumentaram sua capacidade de 120.910 para $176.834(46,25 \%)$, enquanto as com capacidade entre 1.500 a 2.999 apresentaram aumento de 60.270 para 81.679 $(34,27 \%)$ entre 1998 e 2010, demonstrando o fortalecimento das unidades industriais com maior capacidade de processamento. Já as com capacidade até 599 e entre 600 a 1.499 toneladas/ dia permaneceram estáveis.

De 2009 a 2010, enquanto as unidades menores, com capacidade de processamento de até 599 toneladas/dia, aumentaram sua parcela no processamento total em 8,13\%, e as de 600 a 1.499 toneladas/dia diminuíram em $1,40 \%$, as unidades maiores, com capacidade de processamento de 1.500 a 2.999 e acima de 3.000 aumentaram sua participação em 5,90\% e 16,60\%, respectivamente, reforçando que as processadoras de soja buscam ganhos de escala ao aumentarem o tamanho da planta industrial.

Esse resultado já foi observado também no estudo de Aguiar (1994), que analisou os anos de 1977, 1982, 1989 e 1993, em que as unidades de pequeno porte estavam dando lugar às maiores, demonstrando que havia maior importância na construção de plantas maiores e na desativação das menores.

O que também se verificou foi o aumento da quantidade de unidades paradas no Brasil. As unidades ativas se apresentaram num patamar constante de 2003 a 2010, sendo que, em 2007, apresentou o maior pico de ativas, enquanto em 2010 houve o maior número de esmagadoras paradas. Em 2007, o aumento de ativas pode ser explicado pela abertura de novas firmas, como no Maranhão, onde não havia processadora nos anos anteriores. Já em 2010 houve a maior quantidade de esmagadoras no País, apesar de todas não terem esmagado a soja (ABIOVE, 2011).

Os estados do Rio Grande do Sul e Paraná foram os que apresentaram maior quantidade de esmagadoras que pararam ou foram desativadas.
São Paulo, Mato Grosso do Sul, Goiás, Mato Grosso e Santa Catarina também apresentaram unidades esmagadoras paradas. Pernambuco apresentou uma unidade de esmagamento de soja parada desde 2007. Os estados que não apresentaram unidades paradas foram: Minas Gerais, Bahia, Piauí e Amazonas.

Em relação às unidades ativas, verificouse que os estados com o maior número de esmagadoras são: Paraná e Rio Grande do Sul. Nesses dois estados, no período de 2003 a 2008, houve redução na quantidade de unidades ativas; porém, de 2009 a 2010 houve aumento. Mato Grosso apresentou tendência crescente nos anos observados. Em Goiás, das 15 unidades ativas em 2009, três pararam em 2010. Nos outros estados, as unidades ativas permaneceram.

Esses resultados mostram que muitas esmagadoras estão se deslocando para o interior do Brasil, buscando proximidade com as regiões produtoras de soja e, provavelmente, com as de criação de animais que utilizam a soja como alimentação (ABIOVE, 2011).

\subsection{Conduta das empresas}

A conduta das empresas será discutida em relação às principais esmagadoras de soja no País: as multinacionais Bunge, Cargill, ADM e Louis Dreyfus (Coinbra).

\subsubsection{Bunge}

Processa produtos como soja e trigo, comercializa açúcar, produz fertilizantes, fabrica produtos alimentícios (óleos, gorduras vegetais e margarinas), fornece farinha de trigo e pré-misturas para o setor de transformadores (indústrias de panificação e alimentação fora do lar) e fornece serviços portuários. A Bunge Brasil está presente no País desde 1905, com a participação do capital da S.A. Moinho Santista Indústrias Gerais, e depois comprou empresas de alimentação, agribusiness, químico e têxtil, como a Cavalcanti \& Cia., em 1923, formando a empresa Sanbra, chamada depois de Santista Alimentos. Investiu em fertilizantes, 
explorando a reserva de calcário na Serra do Mar (SP), formando a Serrana S.A. de Mineração.

Em 1996, a Bunge adquiriu a área de soja da Incobrasa (Indústrial e Comercial Brasileira), então a maior esmagadora de soja do Rio Grande do Sul, em um negócio estimado em US\$ 80 milhões; em 1997, a IAP, a Fertilizantes Ouro Verde e a Ceval Alimentos (maior processadora na época), grande processadora de soja e produção de farelo e óleos.

Em 1998, a Bunge cria a Global Market, atual Bunge Global Agribusiness, empresa de atuação internacional voltada para o cliente e responsável pelo comércio internacional de commodities da empresa (SOUZA, 2007).

Em 2000, se uniu com a Ceval e a Santista, mudando o nome para Bunge Alimentos, e comprou a empresa de fertilizantes Manah, formando a Bunge Fertilizantes. Em 2003, inaugurou uma unidade de esmagamento de soja em Uruçuí (PI), a fim de expandir o processamento de soja, utilizando a matéria-prima da região (BUAINAIM et al. [200-]; BUNGE, 2010).

Em 2004, a Bunge adquiriu da empresa Perdigão ativos da esmagadora de soja e refino de óleo, em Marau (RS), o licenciamento das marcas de óleo Perdigão e Borella por um período de sete anos e um contrato de longo prazo em que a Bunge se comprometeu a fornecer farelo de soja para as fábricas de ração animal da Perdigão em Catanduvas (SC), Marau (RS) e Gaurama (RS). Em 2006, a Bunge iniciou suas atividades em Rondonópolis (MT), com a comercialização do açúcar, investindo na usina em Santa Juliana (MG) e adquirindo grande parte das ações da Usina Monteverde (MS). Depois, realizou aquisições do negócio de comercialização de açúcar da empresa Tate \& Lyle, fazendo parcerias para produzir açúcar e álcool, e construindo uma usina no estado de Tocantins (BUNGE, 2010).

A empresa está presente em 16 estados brasileiros com oito indústrias processadoras de soja, 45 silos e seis transbordos. Em Luziânia (GO), onde produz as marcas Salada e Primor, é responsável pelo refino de aproximadamente 6,6 milhões de caixas. A localização do município (região que concentra maior área irrigada do Brasil), a disponibilização de mão de obra e a presença da Região Integrada de Desenvolvimento do Entorno do Distrito Federal (Ride), próxima de Brasília, simplificando os processos operacionais e políticos, são os principais fatores de escolha da implantação da esmagadora no município (PAULO, 2010). Em 2009, a Bunge inaugurou sua nova fábrica de processamento de soja em Nova Mutum (MT), que apresenta capacidade média anual de 1,3 milhão de toneladas de soja.

\subsubsection{Cargill}

Uma das maiores indústrias de alimentos do Brasil. Trabalha com produtos e serviços nos segmentos alimentícios, agrícola, financeiro e industrial, e está no Brasil desde 1965, com a sua origem no campo. A sede no País se localiza em São Paulo (SP), e a empresa possui unidades industriais, armazéns, escritórios e terminais portuários em aproximadamente 130 municípios, configurando-se como a principal exportadora de soja do Brasil. Há cinco principais divisões de negócio na Cargill: agronegócio, alimentos, consumo, gerenciamento de risco e industrial. Possui marcas conhecidas como Liza, Maria, Mazola, Purilev, Gourmet, Olivia, Veleiro, La Española, Gallo e Delverde (CARGILL, 2010).

O complexo soja da Cargill é formado por terminais portuários com instalações próprias, transbordos, armazéns e unidades processadoras e possui seis fábricas no País. Está entre as 15 maiores empresas do mundo e é uma das cinco maiores exportadoras do Brasil.

O aluguel de uma pequena fábrica em São Paulo em 1970 para produzir óleo Veleiro iniciou a Cargill no complexo de soja, cujo primeiro passo foi a construção de uma unidade de processamento de óleo de soja em Ponta Grossa, inaugurada em 1973. Em 1995, a empresa adquiriu as unidades de produção, comercialização e armazenamento da Matosul em Mato Grosso do Sul e São Paulo, e em 1996 entra no setor moageiro, adquirindo a Moinho São Valentin, em Tatuí, São Paulo (SOUZA, 2007). 
Em 1997, a Cargill adquiriu uma unidade de processamento em Três Lagoas (MS). Em Rio Verde (GO), sua unidade foi inaugurada em agosto de 2004, contando com uma planta de processamento, um armazém para estocagem e dois tanques. Para abastecer a indústria, a matéria-prima é adquirida no Centro-Oeste, principalmente em municípios goianos (PAULO, 2010).

Em 2007, a Cargill fechou a indústria processadora de soja em Mairinque (SP), mas inaugurou uma fábrica de processamento de soja em 2007, na Argentina, uma vez que o custo de produção no Brasil é superior ao da Argentina em cerca de $30 \%$, em média.

Em 2009, foi inaugurada a processadora de soja em Primavera do Leste (MT) e, em 2012, tiveram início as operações da usina de biodiesel da Cargill em Três Lagoas (MS), anexada a uma processadora de soja já existente (CARGILL, 2010).

\subsection{Archer Daniels Midland Company (ADM)}

Iniciou as atividades no Brasil em 1997 após a compra de esmagadoras, elevadores de grão e silos. Primeiramente, adquiriu as facilidades portuárias da trading Glencore do Brasil. Depois, comprou o parque industrial de soja da Sadia, incluindo uma fábrica situada em Rondonópolis (MT). Foi a última multinacional a se instalar no Brasil, depois da Bunge, Cargill e Louis Dreyfus. É especializada em processamento de grãos (soja, milho, trigo e cacau) e produção de biocombustíveis à base de soja e milho, e ainda produz ingredientes para alimentos e para a nutrição animal, possuindo valor agregado. É uma das líderes na produção de óleo e farelo de soja, etanol, adoçantes e farinha de milho (ADM, 2010).

Tem quatro fábricas de processamento de soja que foram adquiridas da Sadia. Em Rondonópolis (MT), há uma fábrica misturadora de fertilizantes e também uma usina de biodiesel que utiliza óleo de soja como matéria-prima, se localizando estrategicamente próxima à indústria de esmagamento de soja, utilizando o produto ofertado pelos produtores, conseguindo, assim, maximizar os recursos de transporte e processamento da região.

Em 2007, iniciou sua fábrica de biodiesel em Rondonópolis (MT), utilizando o óleo de soja como matéria-prima fabricada na indústria processadora local. Em 2010, anunciou a instalação de uma nova fábrica de processamento de soja no Paraguai, a fim de fortalecer seus negócios no País, e em janeiro de 2013, foi concluída uma usina de biodiesel em Joaçaba (SC), onde já existe uma esmagadora de soja.

A empresa tem em torno de 70 silos localizados nas regiões produtoras de soja, no Sul, Sudeste e Centro-Oeste do Brasil. Em Catalão (GO) e Paranaguá (PR) estão localizadas as outras duas misturadoras de adubos e, em Ilhéus (BA), fica a indústria processadora de cacau. A empresa utiliza três transportes: rodoviário, ferroviário e fluvial (ADM, 2010).

\subsubsection{Louis Dreyfus}

Multinacional francesa presente no Brasil desde o início da década de quarenta, sendo que, em 1942, consolidou sua participação interna quando adquiriu a Comércio e Indústrias Brasileiras Coinbra S.A. Em 1990, foi inaugurada uma unidade na cidade de Jataí (GO). Em 1996, incorporou as indústrias de esmagamento da Anderson Clayton; em 2004, inaugurou uma unidade de processamento de soja em Alto Araguaia (MT), mas, em 2003, havia fechado as unidades de processamento em Orlândia (SP) Londrina (PR) e Cruz Alta (RS), por inviabilidade econômica. As outras três unidades localizadas em Mato Grosso, Paraná e Goiás aumentaram as capacidades processadoras a fim de suprir o fechamento das outras (LOUIS DREYFUS, 2010).

Em 2009, a Louis Dreyfus e a Amaggi formaram uma joint venture no segmento de grãos, para se fortalecerem nas regiões Norte e Nordeste do Brasil. Um dos aspectos positivos dessa região é o investimento por parte do governo em infraestrutura, beneficiando o escoamento da produção, que tem aumentado. 
Atualmente, a empresa industrializa, exporta e comercializa soja, óleo, farelo, gorduras e outros derivados da soja, café, algodão, álcool, milho, sucos de laranja, limão, entre outros produtos. A empresa tem fábricas esmagadoras de soja, fábrica de caroço de algodão, usinas de açúcar e álcool, fábricas de suco de laranja, armazéns graneleiros e fazendas de pomares de laranja. As três unidades de processamento de laranja são instaladas em cidades do estado de São Paulo: Matão, Bebedouro e Engenheiro Coelho. Em 2008, a Louis Dreyfus viu a necessidade de entrar no mercado de fertilizantes, realizando parcerias com misturadoras nacionais (LOUIS DREYFUS, 2010).

As esmagadoras como a Cargill e ADM têm investido em usinas de biodiesel, utilizando soja como matéria-prima. Com a elevação da oferta de carne suína e bovina, consequentemente, a demanda pelo farelo de soja como ração animal aumenta. Dessa forma, quanto mais farelo for produzido, haverá maior quantidade de óleo de soja. Porém, como o Brasil é um mercado limitado em demanda por óleo de soja, as esmagadoras têm adotado estratégias para utilização desse produto, como para as usinas de biodiesel. Desde outubro de 2009, por lei, é obrigatória a adição de $5 \%$ de biodiesel no diesel mineral, o B5, embora, a capacidade construída no País é suficiente para o acréscimo de $10 \%$. Assim, as multinacionais esperam que essa porcentagem aumente no mercado brasileiro.

As Tabelas 5 e 6 se referem às localidades, em relação ao porto de Paranaguá, das unidades processadoras de soja ativas das principais empresas no País nos anos de 2003 e 2010.

Tabela 5. Unidades processadoras ativas e suas localidades em 2003

\begin{tabular}{|c|c|c|c|c|}
\hline \multirow{2}{*}{ Localização } & \multicolumn{4}{|c|}{ Empresas } \\
\hline & ADM & BUNGE & CARGILL & LOUIS DREYFUS \\
\hline \multirow{5}{*}{$\begin{array}{l}\text { Próximo ao porto } \\
\text { de Paranaguá }\end{array}$} & Três Passos (RS) & Rio Grande (RS) & Mairinque (SP) & Ponta Grossa (PR) \\
\hline & Paranaguá (PR) & Ponta Grossa (PR) & Ponta Grossa (PR) & Londrina (PR) \\
\hline & Joaçaba (SC) & São Francisco do Sul (SC) & & Cruz Alta (RS) \\
\hline & & Ourinhos (SP) & & \\
\hline & & Esteio (RS) & & \\
\hline \multirow{6}{*}{$\begin{array}{l}\text { Distante do porto de } \\
\text { Paranaguá }\end{array}$} & Rondonópolis (MT) & Rondonópolis (MT) & Uberlândia (MG) & Jataí (GO) \\
\hline & Uberlândia (MG) & Uruiçui (PI) & Três Lagoas (MS) & \\
\hline & Campo Grande (MS) & Cuiabá (MT) & & \\
\hline & & Luziânia (GO) & & \\
\hline & & Campo Grande (MS) & & \\
\hline & & Luís Eduardo Magalhães (BA) & & \\
\hline
\end{tabular}

Fonte: Elaborado pelos autores.

Tabela 6. Unidades processadoras ativas e suas localidades em 2010

\begin{tabular}{lllll}
\hline \multirow{2}{*}{ Localização } & \multicolumn{1}{c}{ ADM } & \multicolumn{3}{c}{ Empresas } \\
\cline { 2 - 5 } $\begin{array}{llll}\text { Próximo ao porto } \\
\text { de Paranaguá }\end{array}$ & Joaçaba (SC) & Rio Grande (RS) & Ponta Grossa (PR) & Ponta Grossa (PR) \\
\hline & Rondonópolis (MT) & Rondonópolis (MT) & Uberlândia (MG) & Jataí (GO) \\
& Uberlândia (MG) & Uruiçui (PI) & Três Lagoas (MS) & Alto Araguaia (MT) \\
$\begin{array}{llll}\text { Distante do porto } \\
\text { de Paranaguá }\end{array}$ & Campo Grande (MS) & Luziânia (GO) & Rio Verde (GO) & \\
& & Nova Mutum (MT) & Primavera do Leste (MT) & \\
& & Luís Eduardo Magalhães (BA) & & \\
\hline
\end{tabular}

Fonte: Elaborado pelos autores. 
Verifica-se a mobilidade das quatro principais empresas da região tradicional para o CentroOeste durante este período. Enquanto em 2003, 13 unidades ativas estavam próximas ao porto, em 2010, havia somente uma de cada processadora principal. Por outro lado, foram criadas quatro unidades processadoras distantes do porto, demonstrando que as empresas têm buscado aumentar sua capacidade instalada, evitando a construção de novas unidades nessas regiões.

A processadora de soja que apresentou maior quantidade de unidades no País foi a Bunge, seguida da ADM, Cargill e Louis Dreyfus, sendo que a Bunge e a Louis Dreyfus têm processadoras de algodão. Apesar de a Bunge ter apresentado maior quantidade de unidades ativas, também apresentou maior quantidade de unidades que estão paradas.

A evolução da quantidade de unidades ativas e paradas durante os últimos anos mostra que as processadoras têm procurado manter a quantidade de ativas. Ao abrirem novas unidades, elas desativam outras que não estão sendo favoráveis a elas, verificando-se, portanto, que elas têm procurado aumentar sua capacidade (ABIOVE, 2011).

A processadora que desde 2006 não apresentou evolução nas unidades ativas e paradas foi a Louis Dreyfus, que, nos últimos anos, investiu em outras atividades, como cana-de-açúcar e fertilizantes.
Em suma, pode-se dizer que essas principais esmagadoras têm se deslocado para a região Centro-Oeste, ao mesmo tempo em que se expandem por meio de fusões e aquisições, sejam elas horizontais ou por conglomerado. Além disso, elas têm optado por aumentar a capacidade de produção ao invés de investir em novas esmagadoras nessas regiões.

\subsection{Desempenho do setor}

Para avaliar o desempenho do setor, partiu-se para a análise dos coeficientes das regressões múltiplas das variáveis, utilizando como dependentes as variáveis preço recebido pelo produtor (Pre), a quantidade de unidades processadoras de soja ativas (Ati) e a quantidade exportada (QuExp) em cada regressão. O teste VIF (Variance Inflation Factor) foi utilizado para analisar a multicolinearidade. Aquelas variáveis que apresentaram VIF $>10$ foram eliminadas do modelo de regressão, por serem multicolineares. Em todos os modelos, o nível de significância do teste $\mathrm{F}$ foi a $1 \%(\mathrm{p}<0,01)$.

O primeiro modelo, com uma amostra de oito estados, cuja variável preço recebido pelo produtor foi a dependente, pode ser observado na Tabela 7.

Verificou-se que as variáveis independentes (CT), (Prod), (Par), (CaAti), (OleFob), (FaChic) e a (Loc) foram estatisticamente significativas,

Tabela 7. Regressão múltipla para o preço recebido pelo produtor (Pre)

\begin{tabular}{ccccc}
\hline Variável & Coeficiente & Erro Padrão & Estatística-T & P-Valor \\
\hline const & 46,267 & 18,64550 & 2,481 & $0,0161 * *$ \\
CT & $-0,372$ & 0,05202 & $-7,142$ & $2,02 \mathrm{e}-09 * * *$ \\
Prod & $-0,006$ & 0,00110 & $-5,517$ & $9,15 \mathrm{e}-07 * * *$ \\
Par & 5,862 & 2,04586 & 2,865 & $0,0059 * * *$ \\
CaAti & 0,002 & 0,00077 & 2,116 & $0,0388^{* *}$ \\
OleFob & 0,096 & 0,01029 & 9,322 & $5,46 \mathrm{e}-013 * * *$ \\
FaChic & 0,910 & 0,04189 & 21,73 & $5,74 \mathrm{e}-029 * * *$ \\
Loc & 80,591 & 10,98260 & 7,338 & $9,56 \mathrm{e}-010 * * *$ \\
$\mathrm{R}^{2}=0,97$ & & & \\
\hline $\mathrm{n}=64,{ }^{* *}$ Significativo a 5\%, ${ }^{* * * \text { Significativo a } 1 \% .}$ & & & \\
Fonte: Elaborado pelos autores. & & &
\end{tabular}


indicando forte poder de explicação dessas em relação ao preço recebido pelo produtor (Pre). As variáveis que não apresentaram efeito marginal esperado foram (CT) e (Par). Acreditava-se que, ao aumentar o custo de produção total (CT), o preço recebido pelo produtor também aumentaria, visto que o mesmo deveria repassar os seus custos para o preço final. Entretanto, observou-se o contrário, demonstrando que, se o custo total aumenta em $\mathrm{R} \$ 1 /$ tonelada, o preço recebido pelo produtor diminui em R $\$ 0,37 /$ tonelada. Isso provavelmente ocorre porque o produtor não consegue repassar imediatamente a variação dos seus custos ao preço recebido, sendo um agente tomador de preço.

Esperava-se ainda que, ao elevar a quantidade de unidades paradas (Par), a demanda pela soja se reduziria, influenciando negativamente o preço recebido pelo produtor. Entretanto, observou-se uma relação contrária, em que, ao aumentar uma unidade parada, o preço recebido pelo produtor se eleva em R $\$ 5,86$, podendo-se inferir que, ao se aumentar as unidades paradas, há concentração das processadoras ativas, mas que ainda não afeta negativamente o preço recebido pelo produtor. Uma possível explicação é que, embora algumas unidades tenham sido fechadas, seu processamento foi deslocado para outra região do País.

A relação da variável (Loc) com a dependente demonstrou que produtores de soja que estão mais próximos do porto de Paranaguá recebem preços melhores.

Analisando-se o segundo modelo, com a variável quantidade de unidades processadoras de soja ativas (Ati) como dependente, foram verificadas as variáveis explicativas que melhor representam o modelo, conforme se observa na Tabela 8.

Apenas a constante não foi estatisticamente significativa. As variáveis (Prod), (Par) e (OleChic) apresentaram sinal contrário do esperado. As unidades ativas poderiam ter sido influenciadas pelo aumento da oferta da soja, enquanto a ampliação do número das unidades paradas reduziria a quantidade de ativas. Porém, o que foi verificado é que, se a produção aumenta em 1.000 toneladas, a quantidade de unidades ativas diminui em 0,1 unidade. Essa relação pode ser explicada porque o aumento da produção tem sido provocado pelo aumento da capacidade das unidades existentes, principalmente no Centro-Oeste brasileiro, conforme as análises das Tabelas 5 e 6 e o Figura 2.

Com relação às unidades paradas, o aumento de uma unidade parada induz à elevação de 0,77 unidade ativa, mostrando que as processadoras estão desativando algumas unidades ao mesmo tempo em que estão abrindo outras, mas num ritmo menor.

A variável (OleChic) não foi um fator favorável na expansão das processadoras de soja,

Tabela 8. Regressão múltipla para a quantidade de unidades ativas (Ati)

\begin{tabular}{ccccc}
\hline Variável & Coeficiente & Erro Padrão & Estatística-T & P-Valor \\
\hline Const & 0,993 & 0,73372 & 1,354 & 0,1796 \\
Prod & $-0,001$ & 0,00006 & $-9,110$ & $5,35 \mathrm{e}-014^{* * *}$ \\
Par & 0,774 & 0,23095 & 3,350 & $0,0012^{* * *}$ \\
CaTo & 0,001 & 0,00004 & 20,860 & $4,26 \mathrm{e}-034^{* * *}$ \\
CaPar & $-0,001$ & 0,00019 & $-5,373$ & $7,45 \mathrm{e}-07^{* * *}$ \\
OleFob & 0,001 & 0,00040 & 2,922 & $0,0045^{* * *}$ \\
OleChic & $-0,002$ & 0,00067 & $-2,492$ & $0,0148^{* *}$ \\
Loc & 1,549 & 0,42795 & 3,620 & $0,0005^{* * *}$ \\
$\mathrm{R}^{2}=0,95$ & & & \\
$\mathrm{n}=88,{ }^{* *}$ Significativo a $5 \%, * * *$ Significativo a $1 \%$. & & & \\
Fonte: Elaborado pelos autores. & & &
\end{tabular}


e analisando-se a (Loc), percebeu-se que a quantidade de unidades ativas está mais concentrada nos estados localizados no Sul do Brasil, perto do porto de Paranaguá. Apesar de as principais processadoras terem se deslocados para estados mais distantes do porto nos últimos anos, o período não foi suficiente para explicar a relação.

O terceiro modelo, com a quantidade exportada (QuExp) como variável dependente, apresentou poucas variáveis explicativas significativas. Apenas a produção, a quantidade de unidades ativas das principais processadoras e a localização foram estatisticamente significativas no modelo. Se a produção aumenta em 1.000 toneladas, a quantidade exportada aumenta em 391 toneladas, enquanto que um aumento de uma unidade das principais processadoras de soja diminui em 22 mil toneladas na quantidade exportada de soja em grão, sugerindo, dessa forma, que o produto pode estar sendo utilizado pelas processadoras, em vez de os estados exportarem a commodity para outros países. Finalmente, a localização dos estados perto do porto de Paranaguá aumenta em 186 mil toneladas a quantidade exportada da soja.

\section{Considerações finais}

Este trabalho tem como objetivo analisar a estrutura da indústria processadora de soja, bem como a conduta das empresas e o desempenho do setor no Brasil num período mais recente.

Os estudos anteriores apresentaram forte tendência de expansão da região Centro-Oeste, o que foi verificada também neste trabalho. As principais processadoras de soja têm se posicionado nesses estados, mas elas continuam com unidades na região tradicional.

De maneira geral, no Brasil, há ainda uma tendência de aumento na quantidade de unidades processadoras de soja. Porém, em 2010, o número de unidades paradas foi maior, indicando que não são todas as processadoras que têm utilizado plenos recursos.
As principais processadoras (ADM, Bunge, Cargill e Louis Dreyfus) estão cada vez mais se posicionando de acordo com fatores favoráveis, como um aumento da produção de soja na região de expansão, por exemplo. Verificouse também que, ao mesmo tempo em que as principais processadoras pararam de processar a soja em uma unidade, elas abriram outras em localidades que podiam suprir suas necessidades ou aumentaram a capacidade de processamento de algumas já existentes, o que foi comprovado pelos resultados da análise de regressão.

A ADM e a Cargill estão diversificando ao investir nas fábricas de biodiesel, a fim de aproveitarem melhor todos os subprodutos da soja, como é o caso do óleo de soja, que tem mercado limitado no País.

A localização dos estados próximos do porto de Paranaguá foi um fator favorável para as variáveis preço recebido pelo produtor (Pre), quantidade de unidades processadoras de soja ativas (Ati) e a quantidade exportada de soja (QuExp), o que leva à conclusão de que os estados da região tradicional são os mais beneficiados.

Com este estudo, pôde se verificado que a concentração das processadoras de soja, de certa forma, não tem limitado o desempenho do setor. $\mathrm{O}$ avanço da quantidade de processadoras não tem sido prejudicial ao preço recebido pelo produtor. As indústrias processadoras de soja têm um grande papel para o setor.

Uma limitação desse trabalho foi a indisponibilidade de um banco de dados financeiros referentes às principais processadoras, para considerar seus desempenhos.

\section{Referências bibliográficas}

ADM. Disponível em: <www.adm.com>. Diversas consultas, 2010.

AGUIAR, D. R. D. A indústria de esmagamento de soja no Brasil: mudança estrutural, conduta e alguns indicadores de desempenho. Revista de Economia e Sociologia Rural, Brasília, v.32, n¹, p. 23-46, jan/mar.1994.

ANÚARIO DA AGRICULTURA BRASILEIRA (AGRIANUAL). AgraFNP. 2004 a 2011. 
ASSOCIAÇÃO BRASILEIRA DAS INDÚSTRIAS DE ÓLEOS VEGETAIS (ABIOVE). Disponível em: < http:// www.abiove.com.br>. Acesso em 17 fev. 2010.

ASSOCIAÇÃO NACIONAL DOS EXPORTADORES DE CEREAIS (ANEC). Disponível em: < http://www.anec. com.br/estatisticas.htm > . Diversas consultas, 2010.

AZEVEDO, P. F. de. Concorrência no Agribusiness. In: Economia e Gestão dos Negócios Agroalimentares. São Paulo: Pioneira, 2000. p. 61-79.

BAIN, J. S. Barriers to new competition. Harvard University Press, Cambridge MA, 1956

BUAINAIM, A. M., VIEIRA, A. C. P. e VIEIRA JUNIOR, P. A. Análise da Governança da Cadeia da Soja. Disponível em: <http://ebookbrowse.com/28-gt-antonio-marciobuainaim-vieira-junior-doc-d281337348> [200-].

BUNGE. Disponível em: <http:www.bunge.com.br>. Diversas consultas, 2010.

CARGILL. Disponível em: <http:Cargill.com.br $>$. Diversas consultas, 2010.

CARVALHO, L. H. Poder de mercado na indústria brasileira de esmagamento de soja. 2004.47 p. Dissertação (Mestrado em Economia aplicada) - Universidade Federal de Viçosa, Viçosa.

CARVALHO, L. H. de. e AGUIAR, D. R. D. Concentração de mercado e poder de monopsônio na indústria brasileira de esmagamento de soja. Revista de Economia e Agronegócio, v. 3, n. 3. 2005, p. 323-348

CASAROTTO FILHO, N. Redes de pequenas e médias empresas e desenvolvimento local: estratégias para a conquista da competitividade global com base na experiência italiana. São Paulo: Atlas, 1998.

CERTO, S., PETER, J. P., MARCONDES, R. C. e CÉSAR, A. M. R. Administração estratégica: planejamento e implantação da estratégia. 2. ed. São Paulo: Pearson Education do Brasil, 2005.

COMPANHIA NACIONAL DE ABASTECIMENTO (CONAB). Disponível em: <www.conab.gov.br>. Diversas consultas, 2010.

DALL'AGNOL, A. D., ROSSING, A. C., LAZZAROTTO, J. J., HIRAKURI, M. H. e EMBRAPA. Ata da XXVI Reunião de Pesquisa de Soja da Região Central do Brasil. ISSN 1516-781X. Outubro, 2004.

FARINA, E. M. M. Q. Organização industrial no Agribussines. In: Economia e Gestão dos Negócios Agroalimentares. São Paulo: Pioneira, 2000. p. 39-57.

GUJARATI, D. N. Econometria básica. Rio de Janeiro: Elsevier, 2006. $812 \mathrm{p}$.
IGREJA, A. C., PACKER, M. F. e ROCHA, M. B. A evolução da soja no Estado de Goiás e seu impacto na composição agrícola. São Paulo: IEA, 1988. 20 p. (Relatório de Pesquisa, 16/88).

KON, A. Economia industrial. São Paulo: Nobel, 1999. $186 \mathrm{p}$.

KUPFER, D. e HASENCLEVER, L. Economia Industrial: Fundamentos teóricos e práticas no Brasil. Rio de Janeiro, 2002. 640 p.

LAZZARINI, S. G. e NUNES, R. Competitividade do sistema agroindustrial da soja. V5., São Paulo, PENSA/ USP, 2000.

LEI COMPLEMENTAR № 87, DE 13 DE SETEMBRO DE 1996. Disponível em: < http://www.planalto.gov.br/ ccivil_03/leis/LCP/Lcp87.htm> Acesso em 2010.

LOUIS DREYFUS. Disponível em: <http://www. louisdreyfus.com.br/> . Diversas consultas, 2010.

MAGALHÃES, L. C. G. de. Soja. In: Competitividade de Grãos e de Cadeias Selecionadas do Agribusiness. Brasília: IPEA, 1998. p. 95-141. (Texto para discussão ${ }^{\circ} 538$ ).

MARTIN, S. Industrial economics - economic analysis and public policy. 2. ed. Englewood Cliffs: Prentice Hall, 1993.

MINISTÉRIO DO DESENVOLVIMENTO, INDÚSTRIA E COMÉRCIO EXTERIOR (MDIC). Disponível em: $<$ http://www.mdic.gov.br/sitio/interna/interna.php?ar ea $=5 \&$ menu $=1078 \&$ refr $=1076>$. Diversas consultas, 2010.

MEDEIROS, N. H. e FRAGA, G. J. A Concentração industrial nos agronegócios: Análise do índice CR4 na indústria de refino de óleo de soja. In: Anais do XL Congresso Brasileiro de Economia e Sociologia Rural. Passo Fundo, jul. 2002.

PAULO, A. B. Esmagadoras de Sojas dos estados de Mato Grosso do Sul e Goiás. Esalq-Log. Piracicaba, 2010. 31 p.

PINAZZA, L. A. Cadeia produtiva da soja / Ministério da Agricultura, Pecuária e Abastecimento, Secretaria de Política Agrícola, Instituto Interamericano de Cooperação para a Agricultura. Brasília: IICA : MAPA/ SPA, 2007.

POSSAS, M. L. Estruturas de mercado em oligopólio. 2. ed. São Paulo: Hucitec, 1990. 191 p.

RESENDE, M. e BOFF, H. Concentração industrial. In: Economia industrial: fundamentos teóricos e práticas no Brasil. Rio de Janeiro, 2002. 640 p.

RESENDE, M. Medidas de concentração industrial: uma resenha. Análise Econômica. Ano 11. março e setembro/1994. 24-33 p. 
REVISTA EXAME. Melhores e Maiores 2006.

REVISTA EXAME. Melhores e Maiores 2007.

REVISTA EXAME. Melhores e Maiores 2008.

REVISTA EXAME. Melhores e Maiores 2009.

SCHERER, F. M. Industrial market structure and economic performance. Michigan: Rand Mcnally \& Company., 1970.

SOUZA, J. F. D. de. Integração Vertical e Financeirização: O Caso da Agroindústria Processadora de Grãos no Brasil. Dissertação. Universidade de São Paulo. Escola Politécnica. São Paulo: USP 2007, 147 p.

SOUSA, L. G. Economia Industrial. Edicion digital. Disponível em: <www.eumed.net/libros/2005/lgs-ei/. 2005>. Acesso em 24 fev. 2010.

VASCONCELOS, M.A. S. e GARCIA, M. E.; Fundamentos de economia. 2. ed. São Paulo: Saraiva, 2005.
WARNKEN, P. A indústria de processamento da soja. Revista de Política Agrícola, ano 7, n.4, out./dez. 1999.

WILLIAMS, G. W. e THOMPSON, R. L. A indústria de soja no Brasil: uma estrutura econômica e politicas de intervenção do governo no mercado. Brasília, 1988. 80 p. (Coleção Análise e Pesquisa, 34).

WRIGHT, P., KROLL, M. J. e PARNELL, J. Administração estratégica: conceitos. São Paulo: Atlas, 2007.

ZYLBERSZTAJN, D. Estruturas de Governança e Coordenação do Agribusiness: Uma aplicação da Nova Economia das Instituições. Tese de Livre Docência. Universidade de São Paulo. Faculdade de Economia, Administração e Contabilidade. São Paulo: USP 1995, 239 p.

ZYLBERSZTAJN, D. Papel dos Contratos na Coordenação Agro-industrial: um olhar além dos mercados. In. Revista de Economia e Sociologia Rural. Sociedade Brasileira de Economia e Sociologia Rural vol. 43. n. 3. Brasília: SOBER, jul/set 2005. p. 385-420. 